\title{
The Effect of Different Filling Materials Used on Immature Maxillary Central Teeth with Different Apical Diameters on Fracture Resistance
}

\author{
Leyla Benan Ayranci ${ }^{1(\underline{I D})}$, Ahmet Cetinkaya $^{1(\underline{I D})}$, Alper Ozdogan ${ }^{2(\underline{I D})}$, Serkan Ozkan ${ }^{3(\underline{I D})}$, \\ ${ }^{1}$ Department of Endodontics, Faculty of Dentistry, Ordu University, Ordu, Turkey, \\ ${ }^{2}$ Department of Prosthodontics, Faculty of Dentistry, Ataturk University, Erzurum, Turkey, \\ ${ }^{3}$ Department of Orthodontics, Faculty of Dentistry, Ordu University, Ordu, Turkey,
}

Copyright@ Author(s) - Available online at https://dergipark.org.tr/en/pub/mbsjohs

Content of this journal is licensed under a Creative Commons Attribution-NonCommercial 4.0 International

License,

Received: 07 September 2020, Accepted: 31 January 2021, Published online: 30 April 2021

(C) Ordu University Institute of Health Sciences, Turkey, 2021

\begin{abstract}
Objective: This study aims to investigate the effect of different treatment options on immature maxillary central teeth simulated with two different apical diameters on fracture resistance.

Methods: Forty-eight maxillary central teeth with a singular root canal were collected for this in-vitro study. The specimens were decoronated to $17 \pm 0,12 \mathrm{~mm}$ long for ensuring standardization. All samples were randomly divided into two groups: $1,2 \mathrm{~mm}$ group $(\mathrm{G} 1)$ prepared with No. 4 Peaso Reamer and $1.8 \mathrm{~mm}$ group (G2) prepared with No. 6 Peaso Reamer. Each parent group is divided into 4 subgroups ( $\mathrm{n}=6$ ) to form treatment groups. The positive control group was prepared without the access cavity to simulate the immature tooth $(\mathrm{P})$ and negative control $(\mathrm{N})$ group was prepared and filled calcium hydroxide. In group 3 MTA was condensed with a hand plugger to obtain a $3 \mathrm{~mm}$ thick apical plug and remaining parts of the canals were filled with Guttaflow Bioseal cold filling system $(\mathrm{G})$. In group 4, simulated immature roots were filled completely MTA (M). All samples were kept at $37^{\circ} \mathrm{C}$ and $\% 100$ humidity for four weeks. Fracture test was performed by applying a load at an angle 135 degrees to the long axis of the teeth until a fracture occured using a universal test device.

Results: There was a statistically significant interaction between apical enlargement diameter and fill type on fracture resistance $(p<0,05)$. The fracture resistances of the negative control groups in both of group 1 and group 2 were significantly different from those of the other groups $(\mathrm{p}<0,05)$. There was no statistically significant difference in fracture resistance according to filling type in $1,2 \mathrm{~mm}$ apical diameter groups (p>0,05). GuttaFlow (G) group in the 1,8mm apical diameter group has the highest fracture resistance while the MTA (M) group has the closest fracture resistance to the negative control group.

Conclusion: Despite the restrictions in our study, the backfilling with GuttaFlow Bioseal in large apical diameter teeth may be beneficial in terms of fracture resistance.
\end{abstract}

Key words: Immature teeth, fracture resistance, MTA

Suggested Citation: Ayranci LB, Cetinkaya A, Ozdogan A, Ozkan S. The effect of different filling materials used on immature maxillary central teeth with different apical diameters on fracture resistance. Mid Blac Sea Journal of Health Sci, 2020; 6(3):281287.

Address for correspondence/reprints:

E-mail: dt_lbenan@hotmail.com

Leyla Benan Ayranci

Telephone number: +90 (452) 2127245 


\section{Introduction}

In childhood age traumatic dental injuries usually occur and most effected teeth are maxillary central incisors. Especially if pulp necrosis develops due to traumas occurring before completing the root development, effects such as stopping root development and apical closure cannot be achieved (1). Root canal treatments of immature teeth have been a problem due to the open apex, thin dentin wall and wide canal. These teeth are very susceptible to fracture (2).

Due to the incomplete root development in immature teeth, it makes it difficult for the root canal filling to provide an effective plug in the apical third (3). Various treatment techniques have been presented to solve the problem of apical patency in immature teeth. Among these techniques, the apexification technique offered by a researcher was the most preferred application (4). Calcium hydroxide $(\mathrm{Ca}(\mathrm{OH}) 2)$ has been widely accepted for the development of root apex in the treatment of apexification (5). Although used effectively, it has disadvantages such as patient compliance and multiple visits, the risk of re-infection and predisposition to fracture of the tooth (6). In situations like this, regenerative endodontic treatment options should be considered by the clinician to restore the vitality of the tooth and create an apical barrier.

Apexification treatment is used when the regenerative method is not generally considered an option or when regenerative therapy fails (7). In recent years, tricalcium silicate involving cements such as Mineral Trioxide Aggregate (MTA), Biodentin are widely used in endodontics rather than traditional calcium hydroxide. It is the most accepted materials due to its ability to be applied in single visit, superior sealing properties, high biocompatibility and antibacterial effects $(8,9)$. In the use of tricalciumbased materials such as MTA, a strict plug is compresed into the apical third of the root that stimulate a calcified barrier formation in the periapical zone. However, the average MTA thickness used as the apical plug is an argumental treatment procedure, and the risk of fracture remains as the dentin wall thickness is still thin. In order to use the various advantages of MTA and increase the fracture resistance of the tooth, the rest portion of the root canal can be filled with gutta-percha or similar materials after the apical plug with optimum thickness is formed (10).

Silicon-based endodontic sealers stand out with their biocompatible properties (11). These sealers include specifically Guttaflow(Coltene Whaledent, $\mathrm{GmbH}+\mathrm{Co} \mathrm{KG}$, Langenau, Switzerland), a combination of gutta-perka powder, polydimethylsiloxane and added nanometer-sized silver particles for antibacterial features (12). GuttaFlow2 (Coltene Whaledent, $\mathrm{GmbH}+\mathrm{Co} \mathrm{KG}$ ) is a cold flowable system that combines the gutta-perka powder form with a particle size and sealing element of less than $30 \mu \mathrm{m}$ and is the enhanced version of its predecessor guttaflow (13). GuttaFlowBioseal (coltene/whaledent AG, Altstatten, Switzerland) was developed as a new material by adding calcium silicate particles into the mixture of Gutta-percha powder and polydimethylsiloxane and aimed at low cytotoxicity and high cell viability (14). There is no study on the stress generated by Guttaflow Bioseal sealing agent in the canal and the resistance of the root canal to fracture. Therefore, the objective of the present investigation is to assess the difference in fracture resistance values of simulated immature teeth with different MTA thickness and different filling materials. One null hypothesis was that root canal obturation procedures would affect the fracture resistance values of simulated immature teeth and it is hypothesized that different apical diameters would differ the fracture resistance values.

\section{Methods}

One hundred human maxillary central teeth with noncarious, approximately similar buccolingual and mesiodistal dimensions and extracted for periodontal reasons were collected from Ordu University Oral and Maxillofacial Surgery. The roots were metered with a digital caliper (Teknikel, Istanbul, Turkey) in three root regions. For standardization similar fortyeight teeth with a size of $17 \pm 0,12 \mathrm{~mm}$ were regulated. For avoiding calsification, resorptive defects and extra canals, periapical radiographs were taken for mesio-distal and bucco-lingual directions. Fourty eight teeth randomly seperated into two main groups based on the apical diameter. Each group were randomly divided into four subgroups $(n=6)$. Positive control groups were prepared without any access cavity preparation for simulating immature teeth $(\mathrm{P})$. In the positive control groups the specimens were standardized using peeso reamers from in the way of apical to the coronal. The apical $2 \mathrm{~mm}$ of each root for $1,2 \mathrm{~mm}$ diameter groups (G1) and $2 \mathrm{~mm}$ of each root for $1,8 \mathrm{~mm}$ diameter groups (G2) was removed using low speed diamond saw (Diamond Disc Superflex 910S/220, North Bel, Italy). For simulate immature roots, canals were instrumented until 4 Peeso reamer (Mani inc, Tochigi, Japan) reached the apex in Group 1. In Group 2, the root canals were instrumented until 6 peeso reamer reached the apex. Then apical diameters were checked by digital calippers. If the 
specimens have less than $1,2 \mathrm{~mm}$ and 1,8 $\mathrm{mm}$ apical diameters, extra enlarging with K-Files (Dentsply Maillefer, Ballaigues, Switzerland) were performed until obtained necessary wideness. Each root canal was irrigated with $3 \mathrm{ml} 2,5 \%$ sodium hypochlorite and $3 \mathrm{ml}$ distilled water after the instrumentation. The root canals belonging to the negative control groups were filled with calcium hydroxide (Calcicur; Voco,Cuxhaven, Germany) dispensed through a syringe tip and sealed with temporary filling material (Cavit; 3M ESPE, Germany). After these prosedures the specimens were stored in $100 \%$ humidity at temperature of $37^{\circ} \mathrm{C}$ for 4 weeks. In Group 3, MTA (Angelus, Londrina, PR, Brazil) was prepared according to the manufacturers'instructions and to form a $3 \mathrm{~mm}$ thick apical plug MTA was positioned in the simulated immature roots with a hand plugger from the coronal access. Then the rest of the root canals were filled with Guttaflow Bioseal (coltene / whaledent AG, Altstatten, Switzerland) cold filling system until the cementoenamel junction. In group 4, MTA was completely obturated into the simulated immature roots to the semento-enamel junction. For confirming the root canal obturation and apical plug quality periapical radiographs were taken in both mesio-distal and bucco-lingual directions (Figure 1). All samples were placed in an incubator to supply the environment at $37^{\circ} \mathrm{C}$ and $100 \%$ humidity for 24 hours. Resin composite (3M ESPE, St Paul, MN) restorations were applied to the access cavities of the specimens and at $37^{\circ} \mathrm{C}$ and $100 \%$ moisture for 4 weeks.

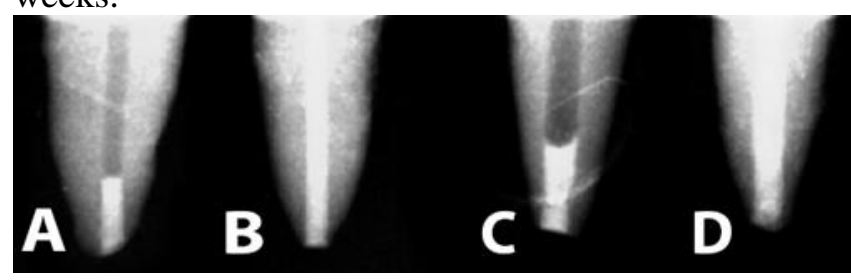

Figure 1. A: $3 \mathrm{~mm}$ apical plug in $1.2 \mathrm{~mm}$ apical diameter group B: Complete obturation with MTA in $1.2 \mathrm{~mm}$ apical diameter group C: $3 \mathrm{~mm}$ apical plug in $1.8 \mathrm{~mm}$ apical diameter group D: Complete obturation with MTA in $1.8 \mathrm{~mm}$ apical diameter group

\section{Fracture Testing}

The roots of all samples were dipped into the wax $0,2-0,3 \mathrm{~mm}$ thick and 2,0 $\mathrm{mm}$ below the sementoenamel junction point for simulation of periodontal ligament thickness. The prepared samples were embedded in autopolymerizing acrylic block at a 45 degree angle and removed after polymerization and purified from wax with hot water. Acrylic resin blocks were sealed with C-type silicone based impresson material (Zeta Plus, Zhermack, Bada Polesne Rovigo, Italy) for simulation PDL and teeth were re-placed in resin blocks. The samples were stored in a humid towel to prohibit desiccation until they entered the cracking test. The force was applied to the long axis of the teeth at 1350 at $1 \mathrm{~mm} / \mathrm{min}$ with a universal test machine until the fracture occured. Values were recorded in Newton units at the time of fracture.

\section{Statistical analysis}

A two-way ANOVA was carried out to invastigate the effects of apical enlargement diameter and fill type on fracture resistance. Data are mean \pm standard deviation, unless otherwise stated. Outliers were evaluated by examination of a boxplot, normality was assigned using Shapiro-Wilk's normality test for each cell of the design and homogeneity of variances was assessed by Levene's test. All pairwise comparisons were run for each simple main effect with reported 95\% reliance intervals and p-values Bonferroniadjusted within each simple main effect. Tukey test was performed to make a pairwise comparisons as there are differences in the fracture resistance between the subgroups in Group 2. All statistical analyses were exerted by the SPSS software (SPSS, Inc., Chicago, IL, USA).

\section{Results}

The mean fracture resistances values and standard deviation of the groups are summarized in table 1. 
Table 1. Mean "Fracture resistance" scores for positive, negative, guttaflow bioseal and MTA fillapex filled $1,2 \mathrm{~mm}$ and $1,8 \mathrm{~mm}$ apical diameter groups

\begin{tabular}{lccccc}
\hline & P(positive) & N(negative) & G(GBioseal) & M(MTA) & p value \\
\hline \multirow{2}{*}{ 1.2mm Apical Diameter } & $1127,07 \pm$ & $841,9 \pm$ & $1017,77 \pm$ & $1070,58 \pm$ & \\
& 230,28 & 215,87 & 173,78 & 230,78 & 0.067 \\
\hline \multirow{2}{*}{ 1.8mm Apical Diameter } & $1180,35 \pm$ & $603,21 \pm$ & $1274,82 \pm$ & $886,82 \pm$ & \\
& 136,66 & 105,1 & $24 ., 92$ & 106,91 & $<0.001$ \\
\hline
\end{tabular}

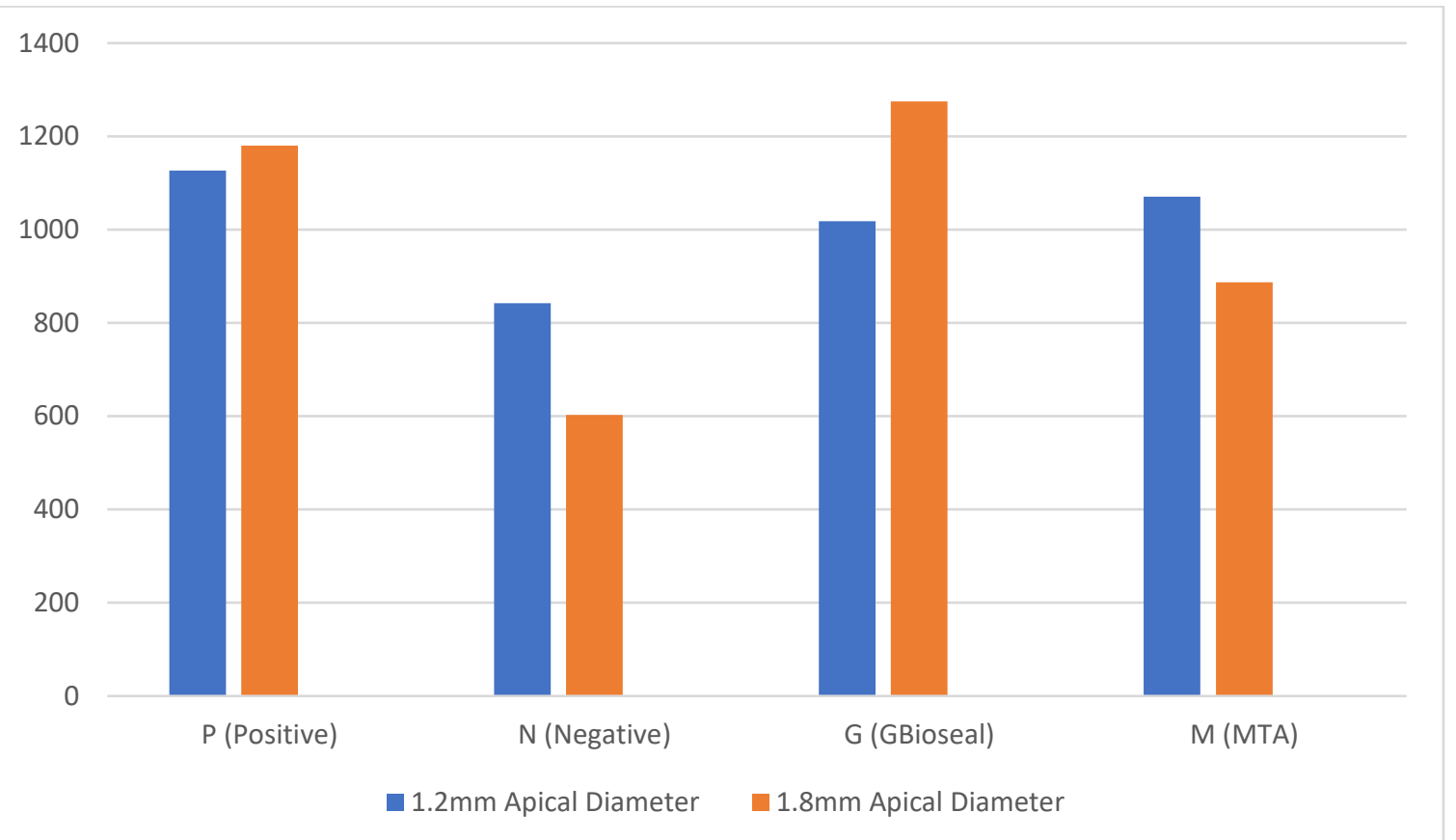

Figure 2. Bar graphics of mean fracture resistance values of groups

A statistically significant difference was reported between different apical diameters $(\mathrm{p}=0,009)$. Negative control groups had the lowest fracture resistance among all subgroups in both main apical diameter groups. The difference between the negative control group and the other subgroups in Group 1 was not statistically significant ( $p>0,05)$, while Group 2 also had a statistically significant difference $(p<0,05)$. There was no statistically significant difference in fracture resistance in $1,2 \mathrm{~mm}$ apical diameter specimens by filling type. Tukey test was performed to make a pairwise comparisons as there are differences in the fracture resistance between the subgroups in Group $2(\mathrm{p}<0,05)$. The fracture resistance value of possitive control group was higher than negative control group and showed a statistically significant difference $(\mathrm{p}<0,05)$. GuttaFlow Bioseal group mean "fracture resistance" value was higher than negative control group in Group 2, the difference is statistically significant $(p<0,05)$. Statistically significant difference was found between GuttaFlow Bioseal group and MTA Fillapex groups in group G2 $(p=, 006)$. However, there was no statistically difference between the filling type groups in Group $1(p>0,05)$. In pairwise comparison analysis there was statistically difference between the filling types of groups $(\mathrm{p}<0,05)$.

\section{Discussion}

In the present study we searched the effect of different apical diameters on the fracture resistance of simulated immature teeth. Different obturation procedures effected the bond strength values in only $1,8 \mathrm{~mm}$ apical diameter simulated group significantly. This hypothesis was partially refused. However, the other hypothesis was accepted, we reported that different apical diameters effected the fracture resistance values significantly

When the pulp is exposed to necrosis as a result of caries or trauma before root growth and development is completed, the apex remains broadly described as open. In this study, the maxillary central teeth were chosen for the experiment because they are more susceptible to external effects and trauma due to their localization (1). Teeth with similar sizes at buccolingual and mesiodistal were included in the 
experimental procedure to provide standardization. In our study, to simulate the immature teeth, the root canals were prepared using sizes 4 and 6 Peeso reamers to mimic Cvek's stage 3 and 4 root development (15). These root development groups have been referenced as representing the most commonly treated immature teeth (16). Prepared samples in this study only take on immature teeth morphologically but not in terms of physiological properties. To test the fracture resistance, simulated immature teeth were buried into acrylic resin block and periodontal membrane simulation was made using a polyether impression material to simulate the clinical situations (17). In addition, the angle between the maxillary and mandibular incisors is 135 degrees in class 1 occlusion, the applied force was loaded on the long axis of the tooth at this angle (18).

Immature teeth are poor in root dentin thickness compared to teeth that have completed root development. The need for restorative materials is increasing as less dentin wall thickness reduces fracture resistance(19). Preceding investigations have appraised the fracture resistance that used diverse root canal filling materials, such as gutta-percha, fiber post or fully MTA in immature teeth (20-22). In many studies, $\mathrm{Ca}(\mathrm{OH}) 2$ apexification significantly increases the risk of root fracture. As a result of denaturation and hydrolysis that occurs in the organic matrix, debilitated dentin can be related with this situation. The risk of fracture becomes more dramatic when root development is incomplete $(6,23)$. In our study, the lowest fracture resistance was observed in negative control groups.

In the literature there are searches about fracture resistance of MTA thickness used in apexification of immature teeth. Bortoluzzi noted that MTA, which is used as an obturation material for immature teeth, increases resistance to root fracture (24). However, there were controversial conclusions about the situation. Cicek et al. (10) reported that the fracture resistance of root canal was completely filled with MTA was lower than the apical $3 \mathrm{~mm}$ plug group. Considering these varied results, the present study compared the complete root canal obturation using MTA or apexification MTA with backfilling with GuttaFlow Bioseal. In this study, different MTA thicknesses were tested on both simulated immatur teeth with an apical diameter of 1,2 mm-1,8 mm and GuttaFlow Bioseal was used for backfilling in $3 \mathrm{~mm}$ apical plug groups.

GuttaFlow Bioseal is a new biocompatible material containing calcium silicate and guttaperka particles. GuttaFlow has apatite forming and bioactive abilities due to its low solubility, good alkalizing activity combined with light calcium release (25). This silicone-based endodontic sealer material has been investigated for its effect on fracture resistance by using it as backfilling after the MTA apical plug. While Guttaflow Bioseal has the highest fracture resistance in the $1,8 \mathrm{~mm}$ apical diameter group, it makes no significant difference in the $1,2 \mathrm{~mm}$ apical diameter group. Difference between the different filling materials and techniques in the $1,2 \mathrm{~mm}$ apical diameter group was not significant this can be because the dentine amount is higher than the $1,8 \mathrm{~mm}$ apical diameter group (19). Especially teeth with wide-apex, it has been observed that using an elastic material after apical plug instead of completely filling the root canal with MTA increases fracture resistance.

\section{Conclusion}

GuttaFlow Bioseal can be an alternative backfilling material after apical plug with MTA to enhance fracture resistance in wide apex teeth such as Cvek's stage III. Our study showed that $\mathrm{CaOH}$ is the worst option in terms of fracture resistance.

Ethics Committee Approval: This study was performed on the extracted human teeth. Clinical Studies Ethics Committee of Ordu University, Faculty of Medicine was not needed.

Peer-review: Externally peer-reviewed.

\section{Author Contributions:}

Concept: L.B.A, Design: L.B.A, A.Ç; Literature search: L.B.A, A.C, Data Collection and Processing: L.B.A, S.O, Analysis or Interpretation: L.B.A, A.C, Writing: A.C, LB.A.

Conflict of Interest: No conflict of interest was declared by the authors.

Financial Disclosure: The authors declared that this study hasn't received no financial support.

\section{References}

1. Andreasen JO, Andreasen FM, Bakland LK, Flores MT. Emergency record for acute dental trauma, and clinical examination form for the time of injury and follow-up examination. Trauma Dent Inj A Manual, 2nd edn Oxford Blackwell Munksgaard. 2003;18-21.

2. Andreasen FM, Andreasen JO, Bayer T. Prognosis of root-fractured permanent incisors-prediction of healing modalities. Dent Traumatol. 1989;5(1):11-22.

3. Silujjai J, Linsuwanont P. Treatment outcomes of apexification or revascularization in nonvital immature permanent teeth: a retrospective study. $\mathbf{J}$ Endod. 2017;43(2):238-45. 
4. Frank AL. Therapy for the divergent pulpless tooth by continued apical formation. J Am Dent Assoc [Internet]. 1966/01/01. 1966;72(1):87-93. Available from: https://www.ncbi.nlm.nih.gov/pubmed/5215726

5. Rafter M. Apexification: a review. Dent Traumatol. 2005;21(1):1-8.

6. Andreasen JO, Farik B, Munksgaard EC. Longterm calcium hydroxide as a root canal dressing may increase risk of root fracture. Dent Traumatol. 2002;18(3):134-7.

7. Jeeruphan T, Jantarat J, Yanpiset K, Suwannapan L, Khewsawai P, Hargreaves KM. Mahidol study 1: comparison of radiographic and survival outcomes of immature teeth treated with either regenerative endodontic or apexification methods: a retrospective study. J Endod. 2012;38(10):13306.

8. Malkondu Ö, Kazandağ MK, Kazazoğlu E. A review on biodentine, a contemporary dentine replacement and repair material. Biomed Res Int. 2014;2014.

9. Torabinejad M, Chivian N. Clinical applications of mineral trioxide aggregate. $\mathbf{J}$ Endod. 1999;25(3):197-205.

10. Çiçek E, Yılmaz N, Koçak MM, Sağlam BC, Koçak S, Bilgin B. Effect of mineral trioxide aggregate apical plug thickness on fracture resistance of immature teeth. $\mathrm{J}$ Endod. 2017;43(10):1697-700.

11.Bouillaguet S, Wataha JC, Tay FR, Brackett MG, Lockwood PE. Initial in vitro biological response to contemporary endodontic sealers. J Endod. 2006;32(10):989-92.

12.Accardo C, Himel VT, Lallier TE. A novel GuttaFlow sealer supports cell survival and attachment. J Endod. 2014;40(2):231-4.

13. Mandal P, Zhao J, Sah SK, Huang Y, Liu J. In vitro cytotoxicity of guttaflow 2 on human gingival fibroblasts. J Endod. 2014;40(8):1156-9.

14.Collado-González M, Tomás-Catalá CJ, OñateSánchez RE, Moraleda JM, Rodríguez-Lozano FJ. Cytotoxicity of GuttaFlow Bioseal, GuttaFlow2, MTA Fillapex, and AH Plus on human periodontal ligament stem cells. J Endod. 2017;43(5):816-22.

15.Cvek M. Prognosis of luxated non-vital maxillary incisors treated with calcium hydroxide and filled with gutta-percha. A retrospective clinical study. Endod Dent Traumatol [Internet]. 1992/04/01. 1992;8(2):45-55. Available from: https://www.ncbi.nlm.nih.gov/pubmed/1521505
16.Plascencia H, Díaz M, Gascón G, Garduño S, Guerrero-Bobadilla C, Márquez-De Alba S, et al. Management of permanent teeth with necrotic pulps and open apices according to the stage of root development. J Clin Exp Dent. 2017;9(11):e1329.

17. Soares CJ, Pizi ECG, Fonseca RB, Martins LRM. Influence of root embedment material and periodontal ligament simulation on fracture resistance tests. Braz Oral Res. 2005;19(1):11-6.

18. Hemalatha H, Sandeep M, Kulkarni S, Yakub SS. Evaluation of fracture resistance in simulated immature teeth using Resilon and Ribbond as root reinforcements-an in vitro study. Dent Traumatol. 2009;25(4):433-8.

19. Stuart CH, Schwartz SA, Beeson TJ. Reinforcement of immature roots with a new resin filling material. J Endod. 2006;32(4):350-3.

20.Chmoldt SJ, Kirkpatrick TC, Rutledge RE, Yaccino JM. Reinforcement of simulated immature roots restored with composite resin, mineral trioxide aggregate, gutta-percha, or a fiber post after thermocycling. J Endod. 2011;37(10):1390-3.

21.Tuna EB, Dinçol ME, Gençay K, Aktören O. Fracture resistance of immature teeth filled with BioAggregate, mineral trioxide aggregate and calcium hydroxide. Dent Traumatol. 2011;27(3):174-8.

22.Wilkinson KL, Beeson TJ, Kirkpatrick TC. Fracture resistance of simulated immature teeth filled with resilon, gutta-percha, or composite. J Endod. 2007;33(4):480-3.

23. White JD, Lacefield WR, Chavers LS, Eleazer PD. The effect of three commonly used endodontic materials on the strength and hardness of root dentin. J Endod. 2002;28(12):828-30.

24.Bortoluzzi EA, Souza EM, Reis JM dos SN, Esberard RM, Tanomaru-Filho M. Fracture strength of bovine incisors after intra-radicular treatment with MTA in an experimental immature tooth model. Int Endod J. 2007;40(9):684-91.

25.Chatterjee S, Mandal D, Biswas I, Shil R, Mazumdar dr paromita, Maiti N. Endodontic management of open apices by two bioactive materials: A case series. Int J Med Heal Res. 2019 Dec 17;5(8):19-22. 